\title{
A Teoria da Aprendizagem Significativa: uma Abordagem na Educação Matemática
}

\author{
Theory of Meaningful Learning: an Approach in Mathematics Education
}

José Milton Lopes Pinheiro*a; Juscimar da Silva Araujo ; Giovana Alves ${ }^{a}$

a'Universidade Estadual da Região Tocantina do Maranhão. TO, Brasil.

*E-mail: jose.pinheiro@uemasul.edu.br

\begin{abstract}
Resumo
Neste artigo se questiona: como a Teoria da Aprendizagem Significativa se apresenta em situações de ensino e de aprendizagem? Trata-se de um recorte compreensivo de um estudo mais amplo, de mestrado, do qual destaca-se a o ensino de matemática visado da perspectiva desta teoria. Ela foi realizada com alunos do curso de Licenciatura em Matemática da Universidade Federal de Juiz de Fora. Nela foi desenvolvida uma proposta que além de ser metodologia da pesquisa, constituiu-se como proposta pedagógica para a futura atuação docente dos sujeitos. Foi promovido um diálogo acerca de temas da Educação Matemática e foram propostas atividades classificadas como exploratórias e investigativas a serem desenvolvidas de modo colaborativo. Os diálogos e o desenvolvimento das atividades foram transcritos. Assumindo uma postura fenomenológica, o pesquisador buscou, junto às transcrições, convergências que pudessem, quando articuladas, trazer compreensões sobre o fenômeno interrogado. Nesse movimento, foram constituídas unidades nucleares, das quais destaca-se para este estudo, a unidade: a presença da Teoria da Aprendizagem Significativa no desenvolvimento das atividades e na aprendizagem de conceitos geométricos. Ao descrever uma síntese reflexiva dessa unidade, articulando compreensões trazidas do presente estudo, explicitando a presença da teoria em todo o processo de aprendizagem, desde o planejamento do professor ao desenvolvimento dado pelos alunos às atividades planejadas, entende-se estar expressando uma compreensão do que interroga a pergunta norteadora deste estudo.
\end{abstract}

Palavras-chave: Teoria da Aprendizagem Significativa. Educação Matemática. Atividades Investigativas.

\section{Resumo}

This article asks: how the Meaningful Learning Theory presents itself in teaching and learning situations? It is a comprehensive cut from a broader study, from master's degree, from which the teaching of mathematics stands out based on this theory. It was carried out with students of the Mathematics course at the Federal University of Juiz de Fora. In it, a proposal was developed that, in addition to the research method, constituted itself as a pedagogical proposal for the future teaching performance of individuals. A dialogue on Mathematics Education themes was promoted and activities, classified as exploratory and investigative, were proposed to be developed in a collaborative way. The dialogues and the development of the activities were transcribed, and assuming a phenomenological stance, the researcher sought, along with the transcriptions, convergences that could, when articulated, bring understandings about the questioned phenomenon. In this movement, nuclear units were formed, of which stands out in this study: the presence of the Meaningful Learning Theory in the development of activities and in the learning of geometric concepts. By describing a reflexive synthesis of this unit, articulating understandings brought by the present study, explaining the presence of theory in the entire learning process, from the teacher's planning to the development given by the students to the planned activities, it is understood to be expressing an understanding of what asks the guiding question of this study.

Keywords: Theory of Meaningful Learning. Mathematical Education. Investigative Activities.

\section{Introdução}

Quando o foco de pesquisa é produção de conhecimento matemático, muitas teorias se apresentam como fundamentação teórica, tais como o Humanismo, o Construtivismo, o Behaviorismo, o Cognitivismo, entre outras. No âmbito da Educação Matemática, esta produção é visada também de diferentes perspectivas, dentre elas a dos Campos Semânticos, da Fenomenológica e a da Educação Matemática Crítica. Isso evidencia que o fenômeno conhecimento matemático se mostra perspectivamente. Voltar-se para ele solicita olhares distintos que, por sua vez, darão compreensões também distintas sobre a matemática e sobre os modos de se estar com ela.

Muitos desses olhares se constituem com compreensões que emergem de estudos de teorias da aprendizagem, dentre as quais destacam-se as de Piaget, de Vygotsky e de Ausubel, que, no âmbito da Educação Matemática, sustentam os trabalhos de Detoni (2000), Onuchic e Leal Junior (2016) e Pinheiro (2013), respectivamente. São aos estudos do psicólogo e pesquisador norte-americano David Paul Ausubel (1918-2008) que este trabalho se direciona, evidenciando suas compreensões e articulando-as como modos de produzir e aprender matemática.

Ausubel é considerado um expoente da linha cognitiva, 
junto com Piaget, Bruner e Novak, e desenvolveu a chamada Teoria da Aprendizagem Significativa ${ }^{1}$ (TAS) cujo princípio é considerar o ensino e a aprendizagem como um conjunto de experiências cognitivas, psicomotoras e afetivas que sustentam e fazem avançar o desenvolvimento do indivíduo. Deste modo, a constituição de conhecimento é "um processo de intercâmbio e negociação de significados; é uma construção humana que coloca em jogo pensamentos, ações e sentimentos e, nesse sentido, é uma construção que se produz em dadas condições e em um determinado contexto" (Santos, 2007, p.174).

Com esse entendimento, objetiva-se explicitar, neste texto compreensões sobre: como a Teoria da Aprendizagem Significativa se apresenta em situações de ensino e de aprendizagem? Trata-se de uma retomada compreensiva da dissertação de mestrado intitulada A Aprendizagem Significativa em ambientes colaborativos investigativos de aprendizagem: um estudo de conceitos de Geometria Analítica Plana, que visou compreender como se dá o envolvimento de professores e futuros professores de Matemática, com uma proposta que intui gerar Aprendizagem Significativa de conceitos de Geometria Analítica Plana, mediada por atividades exploratórias e investigativas em um ambiente colaborativo de Geometria Dinâmica.

No referido estudo, foi realizada uma análise fenomenológica, com a qual se destacou ideias consideradas nucleares à compreensão do interrogado, são elas: os sujeitos enquanto membros de um grupo colaborativo; a postura de sujeitos que exploram e investigam; o suporte do software no pensar e no realizar tarefas no ambiente de Geometria Dinâmica; a presença da Teoria da Aprendizagem Significativa no desenvolvimento das atividades e na aprendizagem de conceitos geométricos. Neste estudo, traz-se a explicitação da quarta ideia nuclear, pois ela trata especificamente da TAS junto ao desenvolvimento de atividades matemáticas, que aqui se propõe focar.

\section{Como e Quando Ocorre Aprendizagem Significativa, Segundo a TAS}

A aprendizagem, do ponto de vista da TAS, é constante; um novo conceito compreendido e assimilado pelo sujeito, torna-se, juntamente com outros anteriormente apreendidos, referência para a aprendizagem de novos significados. Tal conceito direciona-se a uma rede de conhecimentos, chamada pelos cognitivistas de Estrutura Cognitiva, que, segundo Ausubel (apud Moreira \& Masini, 2007, p.14), entendese como "conteúdo total de ideias de um certo indivíduo e sua organização; ou conteúdo e organização de suas ideias em uma área particular de conhecimentos". Trata-se de uma estrutura repleta de significados que podem constantemente ser associados e organizados mediante a necessidade de compreensão de novos significados. A esses saberes, previamente conhecidos pelo sujeito, que constituem sua estrutura cognitiva e que se fazem relevantes à aprendizagem do novo, Ausubel chama de subsunçores. A interação dos conhecimentos subsunçores com o novo conhecimento que se está a produzir provoca mudança em todos os conhecimentos que se entrelaçam no movimento de aprendizagem.

Com o passar do tempo, um material compreendido e assimilado de forma significativa pode sofrer alterações devido as influências que provocam o fenômeno do esquecimento. Tal processo é chamado por Ausubel, Novak \& Hanesian (1980) de assimilação obliteradora. O material assimilado não retroage a ponto de igualar-se ao primeiro subsunçor a ele dirigido, mas torna-se um novo subsunçor, mais abrangente.

As Figuras 1 e 2, abaixo, esquematizam a ocorrência da assimilação e da assimilação obliteradora. Nelas, fica evidente que, um conhecimento novo não se torna um fator isolado ou autossuficiente, mas sim, modifica-se e influencia a aprendizagem significativa de novos conceitos. Os símbolos, a, a', A, A' e a'A', foram escolhidos por Ausubel (1980) para ilustrar o processo de assimilação.

Figura 1 - Assimilação ausubesiana

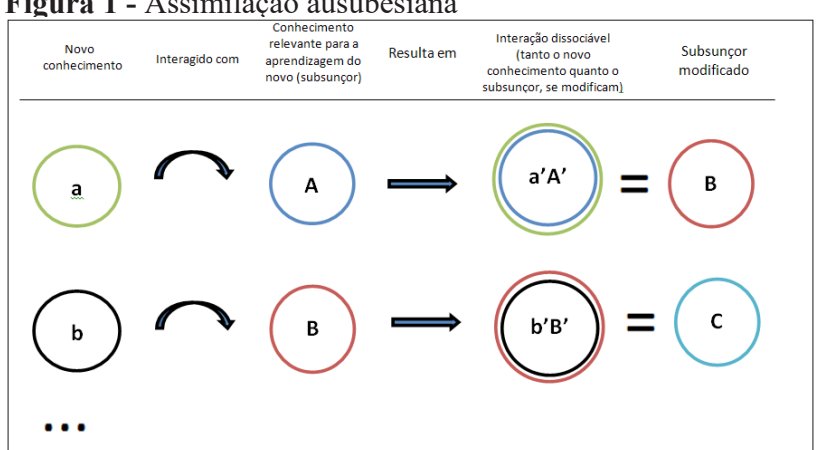

Fonte: Pinheiro (2013, p.35).

Figura 2 - Assimilação obliteradora

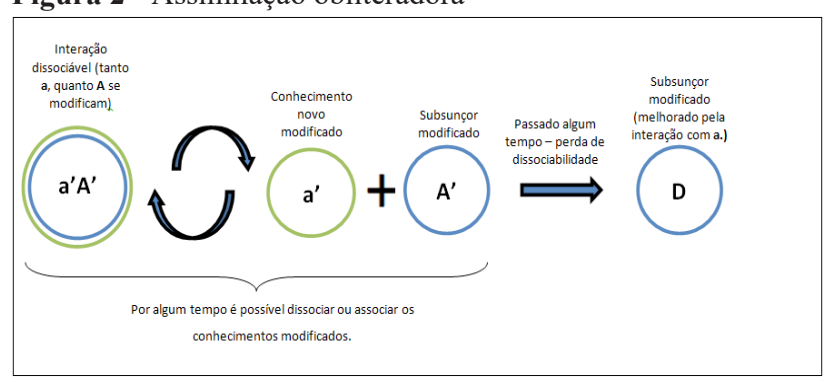

Fonte: Pinheiro (2013, p.35)

Para melhor esclarecimento e entendimento do exposto nas figuras representativas da assimilação ausubesiana, apresenta-

1 Significado, segundo Ausubel, é um produto "fenomenológico" do processo de aprendizagem, no qual o significado potencial, inerente aos símbolos, converte-se em conteúdo cognitivo, diferenciado para um determinado indivíduo. O significado potencial converte-se em significado "fenomenológico" quando um indivíduo, empregando um determinado padrão de aprendizagem, incorpora um símbolo que é potencialmente significativo em sua estrutura cognitiva (Moreira; Masini, 2007, p. 14). Entende-se, aqui, "fenomenológico" como a característica do significado enquanto produzido por alguém, e não estanque do movimento de sua produção. 
se abaixo, um exemplo prático da aprendizagem significativa do conceito de perpendicularismo entre retas.

A noção de retas perpendiculares, apresentada na Geometria Plana como um caso particular de concorrência de retas torna-se subsunçor relevante para a aprendizagem do perpendicularismo de retas na Geometria Analítica Plana.

- Subsunçor (A): As retas $\mathbf{r}$ e $\mathbf{s}$ são perpendiculares quando se intersectarem em um único ponto, sendo que o ângulo formado entre elas é de $90^{\circ}$.

- Conhecimento novo potencialmente significativo (a): As retas $\mathbf{r}$ de equação e s,, são perpendiculares se, e somente se o produto dos coeficientes angulares, e resulte em -1 , ou seja,

$\mathrm{Na}$ interação aqui sugerida, mas pouco explorada, de a com $\mathbf{A}$, ambos se desenvolvem, A torna-se mais consistente, pois é acrescido por a em termos de complexidade e, a também se modifica, uma vez que A fornece um significado simbólico relevante para o mesmo. Assim, o produto da interação de a com A é a'A', um conhecimento significativo, que consiste no tratamento de duas retas perpendiculares como sendo simbolicamente representadas por uma intersecção e um ângulo reto, sendo que as mesmas possuem suas respectivas equações e coeficientes angulares que, ao serem multiplicados, resultam em -1. Com o passar do tempo, a' e A' não voltam a ser a e $\mathbf{A}$, mas a'A' pode ser dissociado em $\mathbf{a}$ ' $+\mathbf{A}^{\prime}$, ou seja, ainda pode-se a pensar as definições separadamente, porém não da mesma forma que anteriormente eram pensadas, pois ambas se modificaram. Ausubel chama de assimilação obliteradora a associação seguida da perda de algumas informações de ambos os conhecimentos, a' e A', ocasionando $\mathbf{D}$, o que torna não mais possível a dissociação. Restando, assim, apenas uma noção mais apurada de retas perpendiculares. D passa a ser, então, subsunçor para aprendizagem de novos conhecimentos, como a conceituação de retas perpendiculares no plano tridimensional, por exemplo.

Referente ao ambiente escolar, Moreira (2006, p.2) compreende que uma aprendizagem significativa acontece mediante potencialidade dos materiais educativos

devem ter significado lógico e o aprendiz deve ter subsunçores especificamente relevantes e a pré-disposição do sujeito para aprender intencionalmente de transformar em psicológico o significado lógico dos materiais educativos.

O professor, ao ensinar um conteúdo, pode deparar-se com o desconhecimento, por parte dos alunos, de materiais vistos como relevantes para a aprendizagem do mesmo. Nesse caso, sugere-se o trabalho com organizadores prévios, que são mecanismos pedagógicos responsáveis por propiciar uma base que sustente a aprendizagem de um novo material. Os organizadores prévios são tratados pelo autor como "pontes cognitivas" que ligam "o que o aprendiz já sabe e o que ele deveria saber a fim de que o novo material pudesse ser aprendido de forma significativa" (Moreira, 2008, p.23).

Sugere-se a apresentação de organizadores expositivos, na evidência de total desconhecimento por parte dos alunos do tema a ser trabalhado. Um contexto mais geral deve ser exposto visando a aprendizagem de temas mais específicos correspondentes. Sugere-se a apresentação de organizadores comparativos, caso o aluno tenha familiaridade com assuntos que possam ser relacionados ao tema em questão. A comparação pode ser trabalhada, também, para estabelecer critérios discriminantes entre ideias novas e ideias já existentes na estrutura cognitiva do sujeito, que aparentem alguma relação, sendo, porém, essencialmente distintas (Correia, 2011).

Moreira (2008) descreve três funções dos organizadores prévios, sendo elas: trazer à luz conhecimentos submersos na estrutura cognitiva, e explicitar seus potenciais de auxílio para a aprendizagem de um novo material; proporcionar uma visão ampla, generalizada e mais abstrata do material que se deseja ensinar, estabelecendo e evidenciando relações com esse novo material; prover um conjunto de ideias e elementos operacionais focados no conteúdo a ser ensinado, que possam ser usados para a aprendizagem significativa desse novo conhecimento.

Conforme a TAS, são três as aprendizagens significativas: Aprendizagem Significativa Representacional, Aprendizagem Significativa de Conceitos e Aprendizagem Significativa de Proposições. A primeira está relacionada com a identificação e relação de símbolos; o símbolo forma um espaço equivalente ao espaço de seu referente; é sobre o novo espaço formado que o sujeito passa a atuar. A segunda é também uma aprendizagem movida por símbolos, no entanto, os mesmos são postos de forma geral, para conceituar ou categorizar características e/ou propriedades de eventos ou objetos. Por exemplo, em Matemática, o ensino de circunferência ou de círculo pode abarcar ambas as aprendizagens: nas séries iniciais a criança aprende e associa a palavra "circunferência" à sua representação geométrica, tal como ilustra a Figura 3.

Figura 3 - Circunferência - exemplo de Aprendizagem Significativa Representacional

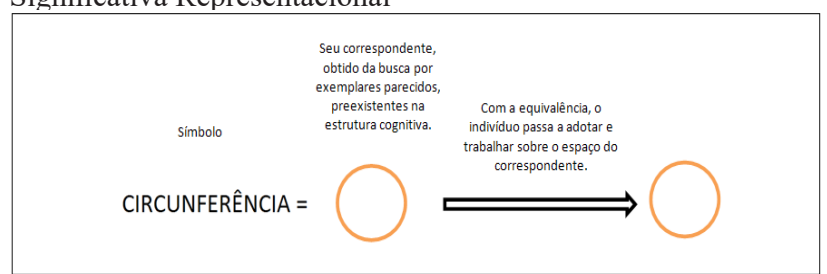

Fonte: Pinheiro (2013, p.37)

Mais adiante, faz-se necessária a conceituação, também simbólica, porém mais elaborada e generalizada, que define, além da forma vista no símbolo, características e propriedades que a constituem. Por exemplo, na curva fechada da representação geométrica da palavra "circunferência", passase a ver pontos; dentro dela trabalha-se a ideia de centro, podendo com isso, trabalhar a ideia de raio. Ao articular essas ideias o aluno pode aprender a definição de circunferência evidenciada em livros e manuais. Na Figura 4, que segue, traz-se uma ilustração desse processo.

Figura 4 - Circunferência: exemplo de Aprendizagem Significativa de Conceitos

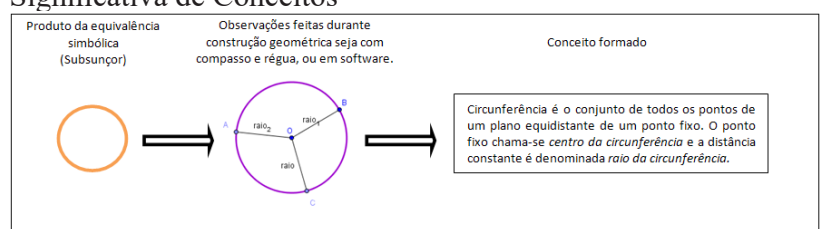

Fonte: Pinheiro (2013, p. 37) 
A terceira, a Aprendizagem Significativa de Proposição, dá-se na interação de uma nova proposição com conhecimentos prévios já existentes na estrutura cognitiva do indivíduo, que são relevantes para o aprendizado da nova proposição. Em Ausubel (2001) consta que esta aprendizagem pode ocorrer segundo três maneiras:

$\checkmark$ De forma subordinada (Figura 5): quando um conceito menos inclusivo é incorporado a um conceito mais geral preexistente, de forma a ambos sofrerem alterações até que seja aprendido significativamente o novo conhecimento:

Figura 5 - Processo de Aprendizagem Significativa Subordinada

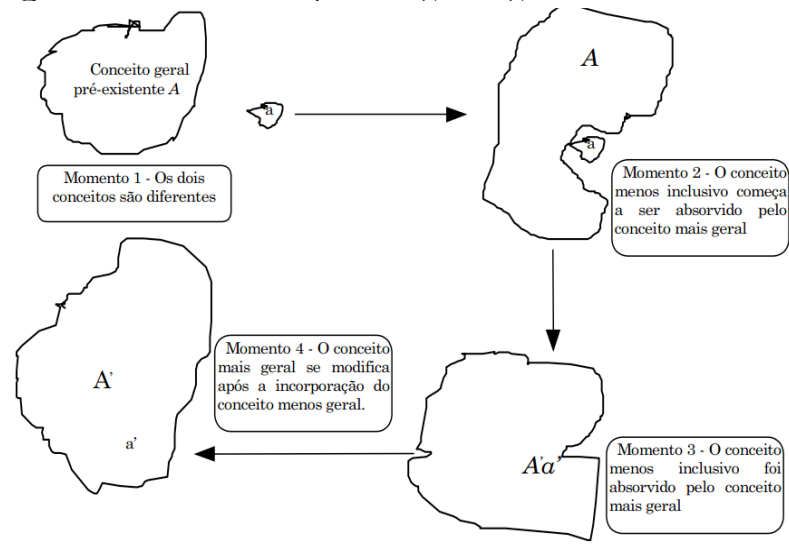

Fonte: Rosa (2003, p.6).

De forma superordenada (Figura 6): quando ocorre o aprendizado de um conceito mais abrangente a partir da união e reorganização de conceitos mais triviais e menos inclusivos contidos na estrutura cognitiva.

Figura 6 - Esquema para a Aprendizagem Significativa Superordenada

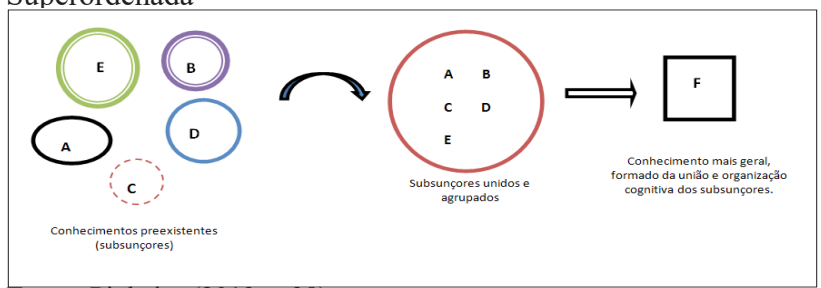

Fonte: Pinheiro (2013, p.38)

$\checkmark$ De forma combinatória (Figura 7): na qual não há subordinação ou superordenação; o novo conhecimento não é formado pela incorporação do mesmo a um conceito mais geral, mas sim pela interação sem ordenação ou agrupamento de conceitos preexistentes.

Figura 7 - Esquema para a Aprendizagem Significativa Combinatória

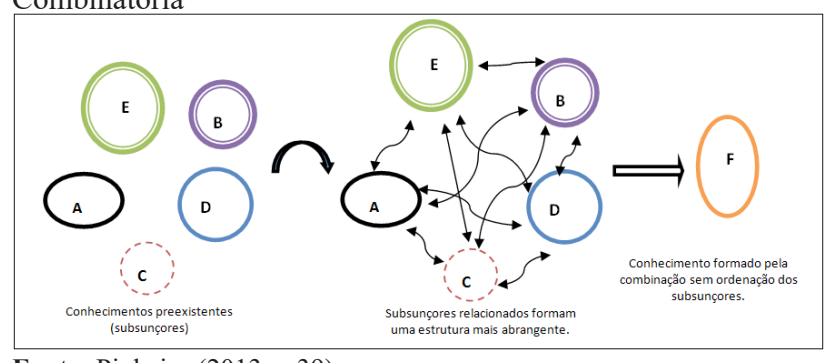

Fonte: Pinheiro (2013, p.39).

A aprendizagem significativa, seja ela representacional, de conceito ou de proposição, ocorre de duas maneiras: por recepção ou por descoberta. Na aprendizagem por descoberta deve-se descobrir alguma relação, princípio ou lei. "Já na aprendizagem significativa por recepção, o aluno recebe a informação pronta, e a função dele será atuar sobre esse material relacionando-o às ideias importantes que estejam disponíveis em sua estrutura cognitiva" (Correia, 2011, p. 52).

\section{Procedimentos de Pesquisa: uma Proposta Pedagógica com a TAS}

Foi proposto um estudo de alguns conceitos de Geometria Analítica Plana valendo-se de atividades exploratórias e investigativas, conforme entendidas por Ponte (2003), sendo elas trabalhadas com o auxílio de ferramentas computacionais constituídas por elementos dinâmicos, construtivos e colaborativos; o Ambiente Virtual de Aprendizagem (AVA) Virtual Math Teams with Geogebra (VMTwG) e o software Geogebra, visando uma aprendizagem significativa, por parte dos sujeitos de pesquisa, alunos do curso Licenciatura em Matemática da Universidade Federal de Juiz de Fora.

Por ser a pesquisa desenvolvida com futuros professores de matemática, compreende-se que não só o tema matemático, mas o contexto que subjaz o mesmo deve ser explicitado como conceito a ser ensinado e aprendido, por ser esse contexto fonte de um pensar pedagógico que possa vir a contribuir com a formação profissional dos sujeitos. Portanto, em campo de pesquisa, como proposta metodológica, faz-se destaque, também, aos temas: Investigação, Exploração e Colaboração.

De acordo com o princípio fundamental da TAS a aprendizagem de um novo conhecimento só é significativa se este for relacionado aos conhecimentos existentes na estrutura cognitiva do indivíduo. Portanto, uma pesquisa ou situação de ensino deve se iniciar com levantamento dos conhecimentos prévios dos alunos sobre o conteúdo a ser trabalhado, bem como os meios e formas de abordagem ao mesmo, no caso desta pesquisa: conhecimentos sobre colaboração, exploração e investigação (temas da Educação Matemática), sobre os softwares de geometria dinâmica, e sobre conhecimentos específicos de Geometria Analítica Plana.

Com esse entendimento, foram promovidos encontros presenciais e virtuais. Virtualmente, foram desenvolvidas atividades geométricas no VMTwG. Presencialmente, se realizou outras atividades geométricas e, anteriormente a essa realização, foi feito levantamento de conhecimentos prévios sobre os referidos temas, por questionário e por dialogo sobre os mesmos. Em seguida, também num diálogo, foram apresentados organizadores prévios relevantes à aprendizagem significativa dos temas.

\subsection{Dialogando sobre temas da Educação Matemática: o trabalho com subsunçores}

Como primeiro tema, promoveu-se uma discussão sobre Atividades Exploratórias. À princípio, foi perguntado aos sujeitos o que entendiam por essa exploração. 
Observada insegurança e constrangimento dos pesquisados, especialmente nas falas, o pesquisador optou por apresentar um contexto mais geral e menos inclusivo, caracterizado por Ausubel (2001) como organização prévia. O organizador sugerido é classificado por Ausubel, Novak e Henesian (1980) como comparativo, uma vez que se buscou no contexto dos sujeitos algo ao qual poderiam associar as semelhanças para compreensão do tema em pauta; foi apresentado o contexto da exploração arqueológica.

Para auxiliar o diálogo, apresentou-se uma figura (Figura 8) que retrata a metodologia adotada para efetuar escavação arqueológica. A figura consiste em uma organização expositiva e ao mesmo tempo comparativa, visto que expõe uma metodologia desconhecida pelos sujeitos e apresenta aspectos comparativos entre contexto arqueológico e o escolar.

Figura 8 - Metodologia de uma escavação arqueológica

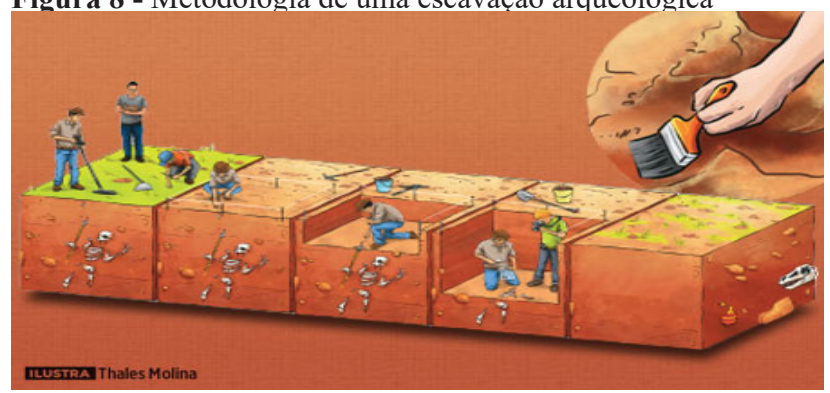

Fonte: Molina (2012)

Na figura observa-se uma técnica para se escavar, que intui não danificar o fóssil, num procedimento cuidadosamente seguido.

Mediante representação, foi pedido aos sujeitos que argumentassem sobre o que entendiam por atividade exploratória, uma vez que com a situação da exploração arqueológica, se podia fazer associações. Destaca-se aqui duas falas:

Roger : Eu acredito que o primeiro momento [se referindo ao primeiro bloco evidenciado na figura] se assemelha com o problema que você dá para o aluno com algumas informações, você esperando que ele chegue a algum ponto que você esperava que ele deveria chegar, se ele chagar neste ponto, ou não chegar, você dá, não uma dica, mas mais material de exploração, que seria a segunda parte [se referindo ao segundo bloco da figura] e assim sucessivamente até ele descobrir o que você tá querendo que seja percebido, ou que quer ensinar. Se ele for caminhando sozinho; "à cheguei aqui", sozinho ele vai pro próximo ponto. Eu acredito que seja mais ou menos este o caminho de uma atividade exploratória.

Daniele: Eu pensei quase o que o Roger falou, mas, antes de chegar na primeira parte, eu acho que você tem que ter um estudo do solo que você vai procurar, por exemplo: tem várias terras e nem todas tem fósseis, então acho que na primeira parte você vai se nortear pra ver se aquilo ali que você quer entra no contexto, por que as vezes você quer muito aplicar uma atividade naquela turma mas aquilo depende do interesse. Então, assim, não é só você querer levar a atividade tem que ter um interesse de volta, porque se não, você vai escavar em uma coisa que não tem nada, de acordo com o interesse dele você vai norteando até chegar onde você vai refinar pra chegar, não pra você descobrir, mas pra ele descobrir.

Entende-se que Roger ${ }^{2}$ expressou o que caracteriza uma atividade exploratória. Sem uma conceituação teórica, ele descreve aspectos que Ponte (2003) aponta serem fundamentais para este tipo de atividade; enfatiza o percurso, que deve ser cuidadosamente preparado pelo professor, evidencia também a autonomia do aluno no tratamento destas atividades e ressalta a mediação do professor, que deve sugerir materiais que permitam ao aluno se desgarrar de um entrave e/ou dar continuidade à aprendizagem de um saber que subjaz a atividade proposta. Percebe-se em Roger o que é dito por Ponte (2003), ou seja, que uma atividade exploratória deve ser bem estruturada, de forma a estimular ações que convergem para um objetivo.

Daniele aponta importantes aspectos que devem ser observados, especialmente no processo de criação e/ou utilização de atividades exploratórias; ela defende um "estudo de solo" como uma pesquisa sobre as experiências dos alunos, que visa conceber dados relevantes para aplicação das atividades de forma a despertar interesse e desafiá-los. Esta abordagem converge à TAS, que assim como Daniele, defende o levantamento de conhecimentos prévios dos alunos, para utilizar destes como caminhos que levam à aprendizagem de novos conhecimentos. Converge-se, também, a questão do "interesse" apontado por Daniele, que assim como a TAS, sugere que haja uma troca, delineada pela atenção, pelo desejo de aprender, para com isto conceber novos significados.

Sobre a temática colaboração em sala de aula, os sujeitos da pesquisa apresentaram muitos conhecimentos prévios, já constituindo assim uma rede significativa de conhecimentos com os quais se poderia avançar um estudo da temática. No entanto, por estar trabalhando como futuros professores, e por estar inserindo-os numa proposta pedagógica, o pesquisador decide por apresentar um organizador prévio comparativo que consiste em um vídeo com menos de dois minutos de duração, que se tratava de um trecho de uma partida de futebol entre Espanha e Venezuela. Destaca-se no vídeo a soberania da seleção Espanhola, que em um minuto e quarenta segundos, com trinta e oito toques, fez com que a bola passasse por quase todos os jogadores do time até marcar o gol.

Após apresentação do vídeo, os sujeitos foram convidados a dialogar sobre possíveis manifestações de colaboração presentes do mesmo. Em poucas palavras, os pesquisados abordaram o que há de essencial no trabalho colaborativo, enfatizaram "o conjunto que possibilita alcançar resultados", "cumprir objetivos".

Fernando: Eu acho que alí [se referindo ao jogo], assim como na sala de aula eles [os jogadores] tinham um objetivo, e o objetivo não foi alcançado só porque o cara chutou a bola pro gol, teve todo um trabalho, desde o zagueiro que saiu lá de traz tocando a bola, até tentar abrir um espaço alí na 
defesa da Venezuela. Então o que é o trabalho colaborativo? Todo mundo teve uma participação importante, aquele toque de alado, o pessoal fala "não! Isso aí é desnecessário, não precisa tocar tanto". É claro que precisa! São passos, você vai vencendo cada um pra chegar no objetivo, acho que isso é o trabalho colaborativo em sala de aula; todos participam, mesmo que seja com uma parte pequena, mas que vai ser importante para o grupo.

Fernando utiliza da organização prévia como subsídio para expor pensamentos sobre a colaboração em sala de aula. As considerações desencadeadas na discussão desse tema destacaram, em especial, o olhar para o indivíduo enquanto membro de um grupo ao qual se espera que seja colaborativo. Os sujeitos apontaram elementos que evidenciam a importância da compreensão do que é ser membro de um grupo colaborativo; relataram a potencialidade de uma terceira ou quarta opinião, do respeito a elas, e contestaram a falta destas opiniões, que pode ser advinda da omissão, do desinteresse ou do desconhecimento e que, portanto, deve-se atentar, para que todos os membros do grupo participem, para que acertem e errem juntos e, com isso, também aprendam juntos.

Assim como nos temas anteriores, foi promovido um discurso inicial sobre as intuições relacionadas à Investigação Matemática e Atividades Investigativas em sala de aula, seguido da apresentação de um contexto generalizado, que possibilitou direcionamentos ao tema específico em questão. Foi apresentado a parte três do episódio de um seriado americano tematizado pela investigação criminal. No vídeo, os investigadores buscavam a captura de um criminoso que tinha fetiche por pés. No vídeo, mostrou muitos aspectos específicos de uma investigação, cuja atenção aos mesmos subsidiou os argumentos dos sujeitos sobre a investigação em sala de aula.

José, um desses sujeitos, aponta: “as vezes tem outros dados em volta, tirando o tema central, que são também importantes pra resolução final", entende-se que "outros dados" são conhecimentos prévios relevantes para o tratamento do novo, conforme defendido por Ausubel (2001). Fernando e Roger concordam que na investigação algo importante a ser feito é "encontrar padrões" para trabalhar sobre os mesmos e descobrir algo que ajude no tratamento da situação problema. Em especial, destaca-se na fala de Roger as perguntas feitas durante a argumentação: "o que eu tenho? O que eu posso conseguir do problema? O que esta situação me dá? Aí eu vou investigar, pra achar essas coisas em comum e saber como a partir delas eu vou responder o problema final". Na mesma linha, Bruna complementa: "acho que na investigação em sala de aula é isso, os alunos devem investigar partindo de perguntas que vão levar eles a algum lugar".

Mediante ênfase dada às perguntas durante uma investigação, o pesquisador levanta a questão: "essas perguntas, é o professor quem às coloca?", o que desencadeou algumas indagações. José, por exemplo, aponta que em uma investigação, "o aluno deve se portar como investigador, ou seja, deve ser autônomo ao ponto de levantar suas próprias interrogações, estas que o nortearia ao investigar".

Roger, questiona sobre a possibilidade de o aluno não conseguir articular uma pergunta relevante para a investigação. Fernando imediatamente responde:

Fernando: $\mathrm{Na}$ investigação acho que o professor deve ficar mediando, ficar analisando cada grupo, vendo o que eles estão fazendo. Ele deve tentar direcionar, mas não entregar o ouro, ele pode questionar: por que você usou isso aqui? Aí ele vai se perguntar: que utilidade tem aquilo? [...] O professor encaminha, mas sem direcionar claramente o que é que é. [demostra segurança na resposta]

A questão da mediação por parte do professor, levantada por Fernando, e confirmada por Ponte (2003) torna-se essencial em sala de aula, especialmente no contexto atual, no qual os alunos não são familiarizados com ambiente investigativo, o que pode tornar o envolvimento com atividades deste cunho difícil e sem significado.

Percebe-se nas interações em torno dos temas propostos, aspectos importantes que distinguem uma abordagem inicial, sem preocupações prévias, de uma abordagem mediada por um objeto que oriente e possibilite argumentos mais elaborados e coerentes. Nesta pesquisa, compreende-se que tais aspectos foram observados tanto no discurso quanto nas expressões faciais e gestos dos sujeitos ao exporem suas ideias. Quando chamados inicialmente a argumentar sobre os temas, houve: inquietação, insegurança, receio de se expressar, algumas falas desfocadas e, às vezes, sem coerência. Após a apresentação dos organizadores prévios, tornou-se evidente a maior segurança por parte dos sujeitos, que souberam estabelecer, organizar e relacionar devidamente seus argumentos. Percebe-se o resgate constante por parte dos sujeitos de suas experiências vividas, pois valeram-se delas para melhor tratar os assuntos ainda não tão conhecidos.

Não se objetiva dizer que a primeira interação sem uma organização prévia não é ou não foi importante, a falta de uma organização inicial, muitas vezes pode propiciar a descoberta e estimular reflexões mais amplas em complexidade. Observa-se na pesquisa que a insegurança inicial impulsionou o diálogo pós-organização prévia; os sujeitos de pesquisa apresentaram dificuldades em argumentar sobre o assunto, o que causou um ar de constrangimento. No entanto, quando lhes apresentados os organizadores, perceberam que possuíam conhecimentos relevantes para tal argumentação, porém, os mesmos não estavam organizados e precisavam de uma ponte que os fizesse convergir.

A concepção de argumentos mais elaborados e consistentes, apresentados pelos sujeitos mediante processor relacional de conhecimentos, pode direcionar a reflexão sugestiva de que tenham aprendido significativamente sobre os contextos pautados. Tal aprendizagem seria por recepção, uma vez que o pesquisador participou efetivamente junto aos pesquisados, apresentando informações importantes que influenciaram na concepção dos saberes. 


\subsection{Propondo atividades metodologia de análise}

Compreender como a Teoria daAprendizagem Significativa se apresenta em situações de ensino e de aprendizagem, solicita um voltar-se a vivências colaborativas. Entende-se que a metodologia fenomenológica se mostra significativa a esse intento, visto que segundo Bicudo (2011) ela propõe o estudo de vivências quando se busca por compreensões originárias, que emergem de uma fazer humano que se presentifica nos modos pelos quais se está com cossujeitos realizando tarefas.

Tendo trabalhado numa abordagem ausubesiana os temas da Educação Matemática: exploração, investigação e colaboração em sala de aula, foram apresentadas aos sujeitos atividades exploratórias e investigativas para serem trabalhadas em grupos colaborativos. O objetivo inicial era que as compreensões constituídas nas primeiras interações pudessem ser solo para o desenvolvimento das atividades, bem como para se pensar práticas de ensino e de aprendizagem, dado o viés formativo dos sujeitos.

Foram desenvolvidas seis atividades, sendo quatro de cunho exploratório e duas de cunho investigativo. Seria relevante, para a compreensão do que emergiu da pesquisa a apresentação de todas as atividades e a análise das mesmas. No entanto, o limite dimensional deste texto possibilita a explicitação de apenas uma atividade. Busca-se com isso, expor, em parte, como a TAS se fez presente nas realizações dos sujeitos.

Portanto, traz-se o desenvolvimento da Atividade Exploratória 1, realizado virtualmente pelo Grupo A (os encontros foram divididos entre os Grupos A, B, C e D). A atividade consiste em efetuar movimentos específicos e atentar-se aos invariantes que se mostram na interface do VMTwG, registrando-os, para em seguida articulá-los de modo a tecer uma definição à cônica expressa junto às variações e aos invariantes provocados pelos movimentos realizados.

$\mathrm{O}$ desenvolvimento da atividade foi transcrito em cenas, nas quais os pesquisados intensificam suas articulações no intuito de perceber e compreender proposições e conceitos em um intervalo percebido pelo pesquisador. Uma cena "[...] se constitui e é explicitada na medida em que releva um todo de sentido dado em suas perspectivas possíveis, desvelando o nexo entre as diversas falas, manifestações e ações ocorridas" (SANTOS, 2013, p.53). Ela inicia-se na intencionalidade da busca por uma totalidade relacionada a um significado em potencial, e finaliza-se quando as percepções provenientes desta busca são dadas como suficientes para tal totalização.

As cenas foram nomeadas conforme cada solicitação da atividade. Elas foram postas como poder-se-á ver no Quadro 1, apresentado logo após a descrição da atividade. Neste quadro, foram articuladas itigativa 1 do Grutividcriçdo a eles como subsunçor para o aprendizado sobre Investigaçle frizar que ela jnterpretações do que entende-se ser o dito pelos sujeitos. Por se tratar da Atividade Exploratória 1 do Grupo A, essas interpretações foram nomeadas de I1-AE1-GA, I2-AE1GA, e assim por diante.

Foram muitos os movimentos e implicações dos mesmos, expressando-se na interface do software Geogebra, acoplado ao VMTwG. Para que o leitor deste texto tenha uma intuição dos movimentos e das expressões gráficas, traz-se algumas imagens, logo após a apresentação da atividade, que segue:

\section{Atividade Exploratória 1}

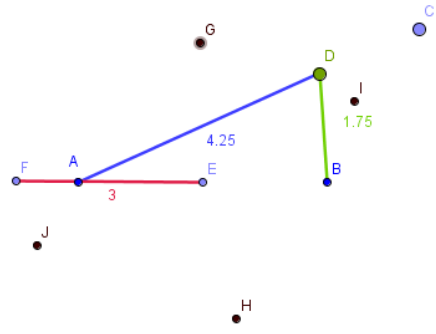

Na aba Geogebra, constam os objetos:

1 - Clique no ícone Take Control, em seguida em mover, selecione o ponto $\mathbf{C}$, e movimente-o como bem entender.

2 - Discutam sobre o que é observável com relação aos segmentos postos quando se movimenta o ponto $\mathbf{C}$.

3 - Na aba "Resumo" crie uma caixa de texto, e sintetize o que foi apresentado e discutido sobre as observações feitas.

4 -Movimente o ponto $\mathbf{C}$ de forma a sobrepor o ponto $\mathbf{D}$ aos pontos pretos apresentados. Discutam sobre o que observaram nessas ações. Na aba "Resumo", apontem resumidamente as indagações do grupo.

5 - Clique sobre o ponto D com o botão direito do mouse, e selecione a opção "Trace On”. Clique novamente, agora com o botão esquerdo do mouse sobre o ponto $\mathbf{C}$ e arraste-o como bem entender.

6 - Escreva na aba "Resumo", o que diz o grupo, sobre: qual figura formada pelo movimento do ponto $\mathbf{D}$, e que elementos da mesma representam os pontos, $\mathbf{A}, \mathbf{B}, \mathbf{D}, \mathbf{E} \mathbf{e} \mathbf{F}$.

7 - Uma definição é construída a partir de propriedades de um objeto. Em Geometria Dinâmica, uma definição pode ser sugerida a partir da invariância de um ou mais elementos, percebida durante alguns movimentos propiciados pelas ferramentas do software.

8 - Levando em consideração os itens anteriores, em especial o item 7, discutam uma definição para a figura encontrada. Em seguida, descrevam tal definição na abra "Resumo".

Atividade Exploratória 1 - Síntese dos movimentos deferidos seguindo o roteiro dado

\section{1 - Mover o ponto $\mathrm{C}$ como bem entender.}

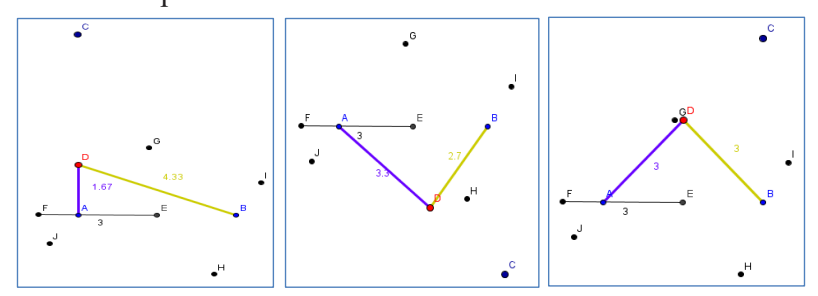


2 - Mover o ponto c de forma a sobrepor D aos pontos pretos da figura

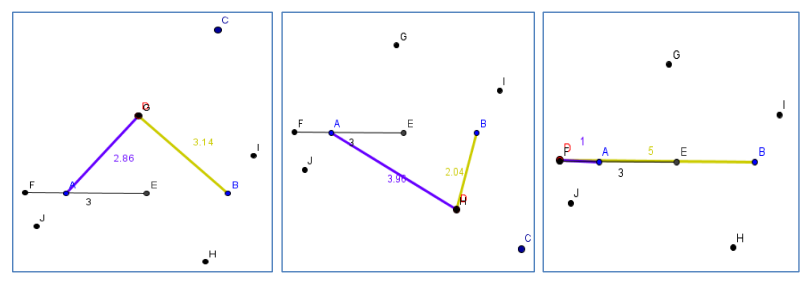

3 - Habilitar rastro em D e mover o ponto C.

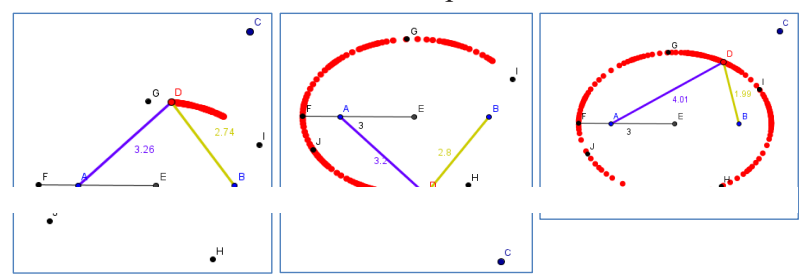

Continua...

Quadro 1 - Desenvolvimento da Atividade Exploratória 1 - Grupo A

\begin{tabular}{|c|c|}
\hline & Atividade Exploratória 1 - Grupo A \\
\hline Mov & r o ponto C como bem entender. Discutir e sintetizar as percepções provenientes do movimento feito. \\
\hline A interação & $\begin{array}{l}\text { LUANA: Que legal! [com empolgação]. Quando movimenta o ponto C, meu ponto D vai movimentando. Ai a reta } \\
\text { AD vai aumentando e a verdinha vai diminuindo [Vendo Lúcia arrastar o ponto C no sentido horário] } \\
\text { LÚCIA: Até ficar coincidentes. Mas, aí (...)[refletindo]. Verde é AB + BD. } \\
\text { LÚCIA: Aí, pode ir lá também [movendo o ponto C no sentido anti-horário] } \\
\text { LUANA: Aí, a verde aumenta e a azul diminui, até coincidir também. Mesma coisa. } \\
\text { LÚCIA: Vai dar a mesma coisa aqui de baixo, dá no mesmo! [afirma após movimentar o ponto C abaixo de EF] } \\
\text { LUANA: É, uma vai aumentar e a outra diminuir do mesmo jeito [reforça e concorda com a afirmação de Lúcia] }\end{array}$ \\
\hline Síntese & $\begin{array}{l}\text { Quando movimentamos o ponto } \mathrm{C} \text { no sentido horário até que os ponto } \mathrm{A}, \mathrm{B} \text { e } \mathrm{D} \text { se alinhem, temos que o segmento } \\
\mathrm{AD} \text { (linha azul) vai aumentando e o segmento } \mathrm{DB} \text { (linha verde) vai diminuindo. Até que o segmento } \mathrm{AD}=\mathrm{AB}+\mathrm{BD} \text {. } \\
\text { Continuando a movimentar o ponto } \mathrm{C} \text { no sentido horário até que os pontos } \mathrm{A}, \mathrm{B} \text { e } \mathrm{D} \text { se alinhem novamente, agora o } \\
\text { segmento } \mathrm{AD} \text { vai diminuindo e o segmento } \mathrm{DB} \text { vai aumentando. Até que } \mathrm{BD}=\mathrm{BA}+\mathrm{AD} \text {. }\end{array}$ \\
\hline Interpretações & $\begin{array}{l}\text { I1-AE1-GA: Os sujeitos têm na atividade abertura para trazer seus conhecimentos prévios de geometria, vendo } \\
\text { objetos se movimentar segundo orientações que propiciam a percepção de regularidade simétrica. } \\
\text { I2-AE1-GA: O dinamismo do software se abre á exploração ao possibilitar a concretização de movimentos pensados } \\
\text { e orquestrados pelos sujeitos. }\end{array}$ \\
\hline & de forma a sobrepor o ponto D aos pontos pretos da figura. Discutir e sintetizar as percepções provenientes do movimento \\
\hline A interação & $\begin{array}{l}\text { LÚCIA: Péraí, deixa eu ver uma coisa aqui [para e pensa], isso aqui é igual a seis, cinco mais um é seis né? Acho que } \\
\text { é, ou não? [A dúvida não diz respeito à soma; mas sim se era esta a observação a ser feita ao sobrepor D ao ponto E] } \\
\text { LUANA: Deixa eu ver [pedindo o controle do Geogebra]. Esse mais esse é..., [somando], é, é seis também! [com } \\
\text { empolgação] } \\
\text { LUANA: No J, também dá seis. } \\
\text { LÚCIA: Então no G também vai dar seis. Olha aí. [presume e pede para Luana sobrepor] } \\
\text { LÚCIA: Então Luana [risos], a gente viu isso [risos], que a soma dos dois segmentos sempre vai dar seis. }\end{array}$ \\
\hline Síntese & $\begin{array}{l}\text { ovimentamos o ponto } \mathrm{C} \text { até que o ponto } \mathrm{D} \text { se sobreponha aos pontos pretos da figura, ao somar a linha azul } \\
\text { a vermelha dá resultado sempre } 6 \text {. }\end{array}$ \\
\hline Interpretações & $\begin{array}{l}\text { I3-AE1-GA: Ao trazer suas experiências para envolvimento com o novo, com uma exploração regida pelo } \\
\text { mover, parar, e o refletir para validar, os sujeitos direcionaram um olhar mais cauteloso, responsável por facilitar a } \\
\text { aprendizagem significativa de uma de constante com potencialidade geradora de um conceito posterior. } \\
\text { I4-AE1-GA: Percebe-se no grupo, o respeito ao espaço pedido e o aceite de um manifesto individual. } \\
\text { I5-AE1-GA: Os aspectos estético-gráficos do software auxiliam no diálogo e síntese conjunta do mesmo. }\end{array}$ \\
\hline & \\
\hline A interação & $\begin{array}{l}\text { LÚCIA: Alá, que lindo! [risos, ao ver o princípio do rastro]. oh! uma elipse! [surpresa ao ver o rastro completar o ciclo] } \\
\text { LUANA: Que bacana! [também surpresa]. Nem pensava em uma elipse. } \\
\text { LÚCIA: Então, o ponto A e B, deve ser o foco da elipse né?[afirma, porém um pouco insegura] } \\
\text { LUANA: É sim, o E é o centro. } \\
\text { LÚCIA: O D é um ponto da elipse né? Não sei. [contrai a voz ao afirmar] } \\
\text { LUANA: O E é o vértice da elipse né? Tem vértice a elipse? Tem! [insegurança seguida de certeza] } \\
\text { LÚCIA: Acho que tem... é tem sim. }\end{array}$ \\
\hline Síntese & O movimento do ponto D, forma uma elipse. Sendo A e B os focos da elipse, D é um ponto da elipse, F é o vértice e E é o centro. \\
\hline Interpretações & $\begin{array}{l}\text { I6-AE1-GA: O rastro propicia a representação gráfica para um símbolo já conhecido "ELIPSE", mas ainda não } \\
\text { previsto, direcionando a percepção de outros ali postos, mas também não percebidas a priori. } \\
\text { I7-AE1-GA: As expressões de concordâncias faladas e as gesticuladas sugerem a empolgação dos sujeitos ao } \\
\text { perceberem colaborativamente objetos mediante elipse concebida da ação deferida. }\end{array}$ \\
\hline & epção de invariantes que sugerem propriedades, elaborar uma definição para a figura encontrada. \\
\hline A interação & $\begin{array}{l}\text { LUANA: Quer ver, vai lá nos pontos dos focos. [Pede a Lúcia para sair da aba resumo e voltar para a tela do Geogebra] } \\
\text { LUANA: Aqui. A distância desse ponto aqui [apontando para o ponto D] até A, mais a distância de D até B dá seis. } \\
\text { LÚCIA: sim, sim. [concorda] } \\
\text { LUANA: Então, a gente tem uma definição! [com empolgação] } \\
\text { LÚCIA: A distância de um ponto mais a distância do foco dois. É isso mesmo. [entendeu, porém expressou-se mau] } \\
\text { LUANA: Uai, dá muito bem pra introduzir elipse assim, a gente não dá no quadro a definição e deixa aluno chegar } \\
\text { nela né, muito melhor! O aluno vai aprender melhor! [Demostra entusiasmo ao termino da atividade] }\end{array}$ \\
\hline
\end{tabular}




\begin{tabular}{|c|l|}
\hline Síntese & $\begin{array}{l}\text { Grupo: A distância de um ponto qualquer da elipse ao foco } 1 \text { mais a distância ao foco } 2 \text { é igual ao dobro da distância } \\
\text { do centro até o vértice da elipse. } \\
\text { Pesquisador: Quando se define algo, não se costuma colocar o nome do objeto a ser definido no meio da definição. } \\
\text { Tentem colocar Elipse no início. } \\
\text { Grupo: Elipse é uma figura plana, em que a distância de um ponto qualquer dela ao seu foco } 1 \text { mais a distância desse } \\
\text { ponto ao foco 2 é igual ao dobro da distância do centro até ao seu vértice. }\end{array}$ \\
\hline Interpretaçõeses \\
& $\begin{array}{l}\text { I8-AE1-GA: O ato de repensar propriedades anteriormente apreendidas permitiu aos sujeitos a percepção do } \\
\text { relacionamento das mesmas com a conceituação do objeto manifestado. } \\
\text { I9-AE1-GA: O convite à reflexão destinado a escrita propicia ao grupo a oportunidade do melhor tratamento e } \\
\text { articulação dos conhecimentos concebidos no diálogo proveniente das ações deferidas. } \\
\text { I10-AE1-GA: A experiência propiciou os sujeitos a percepção do potencial da relação atividade exploratória- } \\
\text { tecnologia, para o ensino e aprendizagem de novos conceitos } \\
\text { I11-AE1-GA: Ao elaborarem uma definição, os sujeitos demonstram ter aprendido significativamente na/pela } \\
\text { colaboração um conceito generalizado para Elipse. }\end{array}$ \\
\hline
\end{tabular}

Fonte: Pinheiro (2013, p.98-103).

$\mathrm{Na}$ análise do desenvolvimento das seis atividades, foram articuladas 250 interpretações. Em um movimento de busca por convergências das mesmas, em um processo amplo e complexo, viu-se emergir sentidos que se mostraram relevantes à compreensão de sua interrogação. Em um novo movimento, agora buscando convergências destes sentidos que se mostraram, o pesquisador constituiu o que foram, para ele, ideias nucleares, que lhe permitiriam dizer da aprendizagem significativa de conceitos geométricos em ambientes de geometria dinâmica. São estas as ideias nucleadas: os sujeitos enquanto membros de um grupo colaborativo; a postura de sujeitos que exploram e investigam; o suporte do software no pensar e no realizar tarefas no ambiente de Geometria Dinâmica; a presença da Teoria da Aprendizagem Significativa no desenvolvimento das atividades e na aprendizagem de conceitos geométricos.

Como este trabalho visa explicitar como a Teoria da Aprendizagem Significativa se apresenta em situações de ensino e de aprendizagem, considera-se relevante trazer uma síntese da quarta ideia nuclear, por entender que com ela e o já explicitado neste texto, pode-se tecer compreensões sobre o aqui interrogado.

$\checkmark$ A presença da Teoria da Aprendizagem Significativa no desenvolvimento das atividades e na aprendizagem de conceitos geométricos.

Apresenta-se, aqui, compreensões sem o intuito de afirmar que a aprendizagem se deu significativamente ou não. Aponta-se o que se entende como possíveis manifestações que direcionam pensamentos e intuições à concepção dessa aprendizagem por parte dos sujeitos. Além disso, faz-se convergir percepções que se mostram características da TAS.

De início, aponta-se o que emergiu como manifestos de conhecimentos prévios, ou, segundo Ausubel, subsunçores. Os sujeitos trouxeram, na interação com seus respectivos grupos, suas bagagens conceituais, incluindo as possibilidades comunicativas. Entende-se como conhecimentos prévios trazidos: saberes sobre as geometrias; conhecimentos previamente trabalhados sobre colaboração; exploração; investigação; vivências com materiais concretos; e a própria dinâmica de comunicação.

À medida que os sujeitos se voltavam às atividades e agiam junto a elas, novos conhecimentos eram aprendidos, os quais, em momentos subsequentes, contribuiam para o aprendizado de conhecimentos outros. Assim, o que se considera aqui como prévio não é algo que está necessariamente distante e/ ou estático, mas, sim, algo que acaba de acontecer e que anima o constante movimento de transformação e aprendizagem.

Compreende-se a presença da TAS, em especial, na evidência do processo relacional que se mostrou quando a estrutura de conhecimentos prévios dos sujeitos abarcou novos conhecimentos, deixando rastro das ligações que fizeram este processo possível. As expressões dos sujeitos permitiram ver esta relação de conhecimentos. Percebe-se que muitos dos conhecimentos que se mostraram em campo não eram desconhecidos pelos sujeitos, mas, também, não eram claramente compreendidos ou estavam parcialmente esquecidoss,ada do jficaçizagem de um novo material, mas de . Nesse caso, não ocorreu aprendizagem de um novo material, mas, sim, a retomada do já aprendido em um processo relacional com o que se preservou sobre este conhecimento na estrutura cognitiva dos sujeitos.

As cenas trazem manifestos que indicam a utilização de organizadores prévios por parte do pesquisador. Foi feito um aporte generalizado em torno de dúvidas e/ou dificuldades. Com esta mediação, os sujeitos conseguiram relacionar informações e vislumbrar modos de se mover diante de dificuldades encontradas. As organizações prévias não foram dadas apenas pelo pesquisador, os próprios sujeitos, ao perceberem o não saber dos companheiros de grupo, empenharam-se em abrir um discurso inicialmente generalizado, caminhando ao que pretendiam focar, às especificidades que os alunos do grupo não conseguiram compreender.

Nas cenas, mostraram-se os três tipos de aprendizagem significativa: Aprendizagem Significativa Representacional, Aprendizagem Significativa de Conceito e Aprendizagem Significativa de Proposição. À primeira, vincula-se às equivalências simbólicas dadas pelos sujeitos. Uma vez creditada por eles a equivalência, passaram durante as atividades a substituir os símbolos previamente conhecidos pelos equivalentes, os quais, na dinâmica do trabalho em grupo foram aprendidos.

Compreende-se a possibilidade de ter ocorrido a 
Aprendizagem Significativa de Conceito. A simbologia previamente conhecida, que ganhou um equivalente ao qual se passou a utilizar, foi concebida de forma mais generalizada. $\mathrm{O}$ empenho sobre as atividades levou os sujeitos a relacionarem conhecimentos prévios aos conhecimentos simultaneamente aprendidos, ou reaprendidos no decorrer da realização das atividades, para, no final, elaborarem os conceitos sobre as figuras geométricas que se mostraram.

Sobre a Aprendizagem Significativa de Proposição, entende-se que ela possa ter ocorrido das três formas possíveis: a) de forma subordinada, na qual percebe-se convergências de manifestos que sugeriram a aprendizagem de conhecimentos mais específicos, utilizando, como ponte, conhecimentos mais generalizados já sabidos, como a retomada da investigação criminal para compreender como proceder na investigação junto às atividades; b) de forma superordenada, quando expressões sugestionaram a concepção de conhecimentos mediante a ordenação de outros já sabidos e os compreendidos durante a atividade. Nesse caso, os conceitos articulados a respeito das seções cônicas resultaram da ordenação formal daquilo que os sujeitos já sabiam até o momento que poderiam compor a definição; c) por combinação: os sujeitos combinaram diversas percepções e conhecimentos sem a necessidade de uma ordenação específica para estruturar outros saberes. Tal aprendizagem, poder ser constatada quando os sujeitos se utilizaram do que sabiam sobre: pontos, distância entre pontos, segmentos, invariâncias, dinamismo dos pontos e segmentos, dentre outros, de forma a combinálos sem manter uma ordem, para com isso perceber e conhecer propriedades específicas.

Compreende-se que as aprendizagens significativas que se mostraram em campo ocorreram por recepção e por descoberta. Quando realizada a organização prévia durante as atividades, sugestiona-se o modo de aprender por recepção: alguns conhecimentos, conforme posto acima, intui-se terem sido concebidos com o auxílio do pesquisador ou de membros do grupo. Nesse caso, o sujeito aprende ao receber informações especificamente relevantes, que norteiam tal aprendizagem. Julga-se que as intervenções de sujeitos e pesquisador, manifestas nas cenas estudadas, por apresentarem informações gerais sobre algo objetivo, corroboraram à aprendizagem significativa por recepção.

No que diz respeito à aprendizagem por descoberta, o pouco envolvimento do pesquisador durante as atividades é um dos dados nos quais aqui se apoia para apontar a possibilidade de ela ter acontecido. Os sujeitos descobriram as relações e propriedades necessárias às atividades, valendose do todo que tinham de conhecimentos, em especial, os especificamente relacionados com o material que trabalharam.

Mesmo sem conhecimento da TAS, que foi apresentada aos sujeitos somente após toda a pesquisa de campo, para não direcionar ações, os sujeitos expuseram pensamentos coerentes à teoria, especialmente ao contrariarem a aprendizagem mecânica; mostraram-se, como futuros professores, adeptos à metodologia das atividades que sugestionou a descoberta de objetos e, consequentemente, a aprendizagem a partir do trabalho e da organização e articulação de tais descobertas. Evidenciaram o intuito de deixar, na prática docente, que seus alunos construam conceitos ao descobrirem por si mesmos, os fundamentos destes, opondo-se a aplicações diretas, sem uma correlação com conhecimentos prévios que compõem a estrutura cognitiva dos alunos.

\section{Dando Conta da Interrogação e Abrindo Possibilidades}

A construção apresentada no tópico anterior traz apenas um modo de compreender como a Teoria da Aprendizagem Significativa se apresenta em situações de ensino e de aprendizagem por tratar-se de uma pesquisa específica, e com sujeitos com suas singularidades. Portanto, entende-se que se tem compreensões com as quais se possa não definir, mas vislumbrar o como, expresso na pergunta diretriz deste trabalho. No entanto, aqui se expõe uma pesquisa de cunho fenomenológico, conhecido pelo rigor analítico e, com isso, o vislumbre permitido não surge num vazio de compreensões, mas numa fundamentação coerente e, portanto, relevante aos estudos cujo foco seja a TAS e o ensino de Matemática.

O fluxo aqui evidenciado expõe que não se realiza uma pesquisa de campo só para cumprir uma formalidade acadêmica; todo o contexto desta pesquisa está inserido na concepção ausubesiana e, portanto, constituiu aos sujeitos não só a aprendizagem significativa de conceitos, mas de um modo de estruturar uma pesquisa e, especialmente, de um modo de pensar o desenvolvimento de aulas de matemática, visando a aprendizagem significativa. Desde o levantamento prévio sobre compreensões de temas da Educação Matemática, passando pela apresentação de subsunçores expositivos e comparativos, avançando à realização das atividades e articulando a análise dos dados de pesquisa, a TAS se fez presente.

Ao articular em linhas gerais a perspectiva de Ausubel sobre a produção do conhecimento, buscou-se convergir pensamentos para a produção do conhecimento matemático, por entender-se que, nessa perspectiva, essa produção se dá da mesma forma evidenciada neste texto. Assim, entende-se que a produção do conhecimento matemático se dá na articulação do novo conhecimento com conhecimentos já existentes na estrutura cognitiva do sujeito, os quais são relevantes para a aprendizagem do novo saber.

As compreensões aqui expressas expõem a relevância, por exemplo, de uma aprendizagem significativa de conceitos em Geometria Plana e da retomada dos mesmos, como subsunçores, para a aprendizagem de conceitos mais complexos em outras geometrias, como a Analítica e a Espacial.

O conhecimento matemático é histórico e temporal, foi se mostrando à humanidade aos poucos, em um movimento que apresentou as primeiras noções de espaço, os primeiros números, avançando às complexas estruturas numéricas 
e às teorias do cálculo. A produção desse conhecimento, da perspectiva ausubesiana, se deu no processo que leva à composição constante da estrutura cognitiva dos estudiosos que se voltaram à Matemática. Todo voltar-se tem solo em conhecimentos já aprendidos. Com isso, todo conhecimento matemático emerge da própria matemática culturalmente e teoricamente conhecida. Ou seja, o matemático produz matemática valendo-se da totalidade de seus conhecimentos, que abarca não só o que aprendeu com outros matemáticos, mas também os saberes que emergem da vivência sociocultural, que permitem não só dizer da Matemática, mas dizer dela aplicada em situações do cotidiano.

Todas as possibilidades de conhecer e produzir matemática, que são abarcadas pela TAS, podem ocorrer por recepção ou por descoberta. Mesmo os primeiros matemáticos se reuniam em torno de problemas que os intrigavam. Com isso, a produção não era individual, mesmo que o mérito muitas vezes fosse destinado a quem sistematizou formalmente todas as discussões e apresentou à sociedade soluções para os problemas. É neste diálogo que se visualiza a intervenção externa e, com isso, vê-se alguns conhecimentos sendo produzidos por recepção. No entanto, mesmo neste coletivo pensante em torno de problemas, houveram momentos de individualidade, em que um matemático, em muitos casos, dedicava sua vida ao propósito de resolver um problema e/ ou produzir uma obra matemática que venha a ser respeitada. Deste fazer, também emergiu muito do que se conhece hoje sobre matemática. Tratam-se de estudos que fizeram emergir, do campo amplo e complexo de uma matemática já constituída, algo novo que saltou aos olhos de quem estava imerso em uma investigação. Trata-se de uma produção por descoberta.

Ausubel não desenvolveu uma teoria direcionada ao contexto escolar. Ele se volta à aprendizagem humana. Pesquisadores e professores podem fazer valer seu legado em contextos aos quais nos voltamos, pois em todos eles o ser humano se faz presente. Assim, pode-se olhar para a escola, para a sala de aula da matemática e propor metodologias que foquem o que o sujeito/aluno já conhece.

A Matemática é uma ciência dentre outras, é uma disciplina do currículo escolar dentre outras. Compreendese que muito se pode aprender e produzir sobre matemática quando visadas outras ciências, pois elas são de algum modo preenchidas por matemática - quando não teoricamente, o são reflexivamente. Assim, outras ciências, outras disciplinas são fontes extensas de subsunçores relevantes à aprendizagem de matemática. Dessa forma, a interdisciplinaridade se mostra também importante nesse movimento de produção de conhecimento matemático, quando olhada na perspectiva da Teoria da Aprendizagem Significativa.

\section{Referências}

Ausubel, D.P. (2001). Aquisição e retenção de conhecimentos: Uma perspectiva cognitiva. Lisboa: Plátano.

Ausubel, D.P., Novak, J.D., \& Hanesian, H. Psicologia educacional. (1980). Educational psychology: a cognitive view. Rio de Janeiro: Interamericana.

Bicudo, M.A.V. (2011). A pesquisa qualitativa olhada para além de seus procedimentos. In: M.A Bicudo, Pesquisa Qualitativa segundo a visão fenomenológica. São Paulo: Cortez.

Correia, W.M. (2011). Aprendizagem Significativa, explorando alguns conceitos de geometria analítica: Ponto e Reta. Ouro Preto: Universidade Federal de Ouro Preto.

Detoni, A.R. (2000). Investigações acerca do espaço como modo da existência e da geometria que ocorre no pré-reflexivo. Rio Claro: Instituto de Geociências e Ciências Exatas, Universidade Estadual Paulista.

Lemos, E.S. (2011). A aprendizagem significativa: estratégias facilitadoras e avaliação. Aprendizagem Significativa em Revista, 1(1), 25-35.

Moreira, M.A., \& Masini, E.F(2007). Aprendizagem Significativa: A Teoria de David Ausubel. São Paulo: Centauro.

Moreira, M.A. (2006). Aprendizagem significativa: da visão clássica à visão crítica. Anais do Encontro Internacional sobre Aprendizagem Significativa, Madri, Espanha, 5.

Moreira, M.A. (2008). Organizadores prévios e aprendizagem significativa. Revista Chilena de Educação Científica, 7(2), 23-30.

Onuchic, L.R., \& Leal Junior, L. C. (2016) A influência da leitura na resolução de problemas: questões de sentidos, significados, interesses e motivações. Revista de Matemática, Ensino e Cultura REMATEC, 11(21), 24-46.

Pinheiro, J.M.L. (2013). A Aprendizagem Significativa em ambientes colaborativo-investigativos de aprendizagem: um estudo de conceitos de Geometria Analítica Plana. Juiz de Fora: Universidade Federal de Juiz de Fora, Juiz de Fora.

Ponte, J.P. (2013). Investigar, Ensinar e Aprender. Actas do ProfMat. Lisboa: APM.

Rosa, P.R.S. (2003). A teoria cognitivista de David Ausubel. Campo Grande. 2003.

Santos, F.M.T. (2007). As emoções nas interações e a aprendizagem significativa. Revista Ensaio, 9(2), 173-178. 